\title{
LIBERALISMO Y MULTICULTURALIDAD EN EL CONTEXTO DE LA GLOBALIZACIÓN
}

\author{
JOSÉ LUIS CASTILLA VALLEJO \\ Universidad de La Laguna
}

\begin{tabular}{ll}
\hline PALABRAS CLAVE ADICIONALES & ADDITIONAL KEYWORDS \\
$\begin{array}{l}\text { Desigualdad, Diferencia, Educación, Politicas de } \\
\text { redistribución y reconocimiento. }\end{array}$ & $\begin{array}{l}\text { Inequality, Difference, Education, Redistribution } \\
\text { and Recognition Policies. }\end{array}$
\end{tabular}

redistribución y reconocimiento.

and Recognition Policies.

RESUMEN. Este artículo trata el enfoque del liberalismo cultural y sus aportaciones al debate sobre la justicia y el multiculturalismo en el contexto de la globalización. El autor plantea la heterogeneidad de este enfoque y señala cómo se asienta en una concepción muy restrictiva de la multiculturalidad y la diferencia. El artículo hace el doble esfuerzo de, por un lado, clarificar el contenido del enfoque del liberalismo cultural, $y$, por otro, criticar el alcance de sus fundamentos y propuestas analisticas. A partir de esas críticas, el objetivo final del autor es proponer elementos alternativos para la configuración de un multiculturalismo complejo que respete una idea amplia de la diferencia.

ABSTRACT. This article focuses on the theoretical approach of the cultural liberalism and its contributions to the debate about justice and multiculturalism in the globalization context. The author shows the internal plurality existing into this approach, and he states that it is based on a very restrictive conception of multiculturality and difference. On the one hand, the article tries to clarify the most important theoretical components of the cultural liberalism approach, and on the other hand, it critizes its foundations and analitical propositions. According to these critics, the author suggests some alternative elements contributing to a more complex conception of liberalism where a wide idea of difference could be acepted.

E-mail: jlcast@ull.es

Revista Internacional de Sociología (RIS)

Tercera Época, No 37, Enero-Abril, 2004, pp. 217-243. 
R I S

REVISTA INTERNACIONAL DE SOCIOLOGIA

Jorge Riechmann*

\section{PRESENTACIÓN}

El liberalismo cultural supone una de las tendencias intelectuales más productivas en los últimos años en el amplio terreno de discusión sobre la justicia y el multiculturalismo. La heterogeneidad del liberalismo cultural, dentro del universo plural del liberalismo a secas, nos introduce en una variante particularmente brillante de estos análisis de la que hemos aprendido a buscar soluciones a problemas de difícil resolución. Pero estas posibles soluciones parecen asentarse en unos terrenos de la multiculturalidad y un concepto de la diferencia particularmente restrictivos. En este trabajo se desarrollará un doble esfuerzo de clarificación de lo que representa este liberalismo cultural y un ejercicio crítico del alcance de sus fundamentos y propuestas analíticas.

Pero una evaluación crítica de semejantes postulados obliga a ofrecer una respuesta a algunas de las dificultades detectadas. En tal sentido, nos parece importante apuntar elementos para la configuración de un multiculturalismo que respete una idea de la diferencia amplia y componga lo que hemos dado en llamar un "multiculturalismo complejo". Lo que se aporta en este sentido no es una teoría hecha (este artículo no tiene tal pretensión); más bien se busca aproximar elementos que a medio plazo puedan dar respuestas a problemas de máxima actualidad, como son los que tienen que ver con los modelos de ciudadanía, con la construcción de tipos de democracia menos perversos y con una respuesta a la actual fragmentación del Estado de Bienestar.

El trabajo fuerza necesariamente una restrictiva selección de lo que denominamos liberalismo cultural. Pero confiamos en que esta fuerte restricción no traicione demasiado el espíritu de lo que muchos de ellos defienden. Como de todas maneras se trata de un campo muy diverso, la dispersión de argumentos parece lo suficientemente amplia como para dar idea al lector de que el continente es más grande que el país que se visita. Lo que ofrecemos, pues, es un análisis crítico de un liberalismo asequible a la discusión intelectual pormenorizada. Decimos asequible porque, como demuestra Ovejero en su interesante trabajo sobre el liberalismo (Ovejero, 2002: 24), éste tiende a configurarse como una construcción normativa e impermeable a un contraste empírico. Es desde

•Del poema "Los proximos diez mil años", de Jorge Riechmann en Viento Sur, n 67, marzo, 2003, p. 104. 
la profunda incomodidad con el pensamiento liberal que se escriben estas líneas. Unas líneas que dejarán para otro trabajo posterior toda la discusión que se deriva de la pugna por los modelos de justicia liberales y su forma etnocéntrica de deslegitimar la tradición de la izquierda postmoderna (que no hay que confundir con un postmodernismo radical de consecuencias mucho más conservadoras).

La importancia del liberalismo en nuestra tradición política occidental (menor en el específico caso español) y su necesaria crítica, así como la importancia del debate que pone en relación la cultura y la justicia, son dos argumentos de peso que justifican la oportunidad de este trabajo de aproximación.

\section{LOS LIBERALISMOS FRENTE AL LIBERALISMO CULTURAL}

Como ya se ha señalado, no es fácil la labor de identificar la política de esta modernidad tardía y contradictoria. Con frecuencia se habla en estos debates en torno a la cultura del pluralismo y las identidades sin asumir la responsabilidad de definir la identidad de la propia política. Como la política, se dice, no es un "sujeto" histórico y físicamente representable, no tiene identidad o no merece la pena reflexionar sobre ella en clave de sujeto. Este engaño compartido (conquista del liberalismo) parece circular bajo el suelo del combate sin salir a la luz de forma clara y explícita, lo que convierte toda discusión en un problema más formal que real, más abstracto que concreto. En este tipo de confrontaciones intelectuales extremas, la política, o satura todos los poros de la discusión, o intenta ser mantenida a raya a fuerza de desvincularla de la acción colectiva. Hasta cierto punto, y no sin cierta sorpresa, la política se ha vuelto adolescente. No sólo pasa por una etapa crítica en la definición de su nueva identidad, sino que, además, lo hace, como no puede ser de otro modo, reutilizando con fuerza renovadora viejas herramientas para su reconstrucción.

En este juego de luces y sombras de la política las culpas no pueden ser repartidas por igual. Los liberalismos son auténticos maestros en el arte de transformar la discusión política en juegos formales (como reza en el diálogo de una película de David Lean: "No me hable de reglas. Esto es una guerra, no una partida de cricket"'), juegos cuya representación más acabada consiste en establecer los marcos normativos a partir de los cuales poder discutir sobre las grandes categorías (autonomía, libertad, igualdad, propiedad) sin que se le mueva un pelo a nadie. La hegemonía liberal empeñada en pensarse y construirse bajo el influjo

' Sussue Hyakawa, en El puente sobre el rio Kwai (1951), de David Lean. Citado por Ovejero (2002: 15). 


\section{RIS}

mayoritario del derecho ha reelaborado el estatus de la política a su antojo y ha aniquilado (o amenaza con hacerlo) otras formas de representarla. Desde este punto de vista, el liberalismo se ha ido configurando como un monoculturalismo de la postpolítica, aquélla que piensa que la acción política, o es política legitimadora, o sencillamente no es.

Cuando decimos que el liberalismo es un monoculturalismo de la postpolítica no queremos decir que sea un todo unitario, un bloque compacto diseñado para establecer un afuera, un impensado de la política, un exterior excluido e inasimilable. Como se ha dicho hasta la saciedad, el liberalismo es muchas cosas al mismo tiempo, y ninguna a la vez. Creo, con Ovejero, que la mejor definición de lo que es el liberalismo es el devenir de una filosofía política hacia el inhóspito fluir de intuiciones deshilachadas ${ }^{2}$; unas intuiciones en las que sus referentes más destacados no comparten ideas comunes ni del Estado de Bienestar, ni del funcionamiento del mercado, ni de los límites normativos del derecho, ni del derecho de autodefensa, ni de la justicia social, ni de la distribución de la renta, etc. En este sentido, el liberalismo es más un frente amplio generador de hegemonía que unas ideas compartidas de acción o reflexión. Una hegemonía cuyo núcleo intelectual duro en el que reconocerse está formado por los siguientes elementos (Ibidem: 265): la existencia de derechos prepolíticos (aquí encontramos el clásico enfrentamiento entre Hobbes, que representa al Estado como la fuente única del derecho, y Locke, para el que existen derechos fundamentales anteriores a la aparición del Estado y que éste no puede suprimir sin abolir la libertad); una neutralidad de las instituciones públicas (que permite la no intromisión del Estado en la definición heterogénea de las formas de vida); una concepción de la naturaleza humana pesimista como "individuos antisociales en sociedad"3 (egoístas, calculadores, racionales, interesados, asociales y sin vocación pública ni preocupación por el interés general); una defensa de la libertad negativa e incómodos con la libertad positiva (la libertad nada tiene que ver con la vida pública, la libertad negativa e incomodidad es "libertad de" no interferencia, mientras que la "libertad para" requiere redistribución para ejercer la capacidad).

Desde el liberal-conservadurismo ("todo va bien en el mejor de los mundos posibles") hasta el social-liberalismo ("todo va mejor en el menos malo de los mundos posibles") $)^{4}$ encontramos sensibilidades distintas a la hora de afrontar de forma pragmática los dos retos fundamentales: salvar al capitalismo de sus

\footnotetext{
2 "El liberalismo, que alguna vez aspiró a ser una filosofía política, aspiración que todavía perdura en algunos esfuerzos académicos, no pasa hoy de ser un conjunto de razonables intuiciones asentadas en nuestra cultura política compartida" (Ovejero, 2002: 263).

${ }^{3}$ Felix Ovejero lo define como el PIAS (Paradigma de Individuos Antisociales en Sociedad). (Ibidem: 40).

${ }^{4}$ Estas síntesis las hemos tomado del trabajo de Ródenas (1992: 38-39).
} 
contradicciones y atacar toda forma de representar la política que no pase por sus principios fundamentales. El nuevo contrincante ya no es el socialismo. Hace más de una década que para los liberales este contrincante histórico ha dejado de existir. El socialismo es algo así como una pesadilla del siglo XX que no volveremos a tener. Sin embargo, el socialismo, en su desbandada, ha generado una diáspora de ubicación heterogéneas: los intelectuales "decentes" que, en su esfuerzo por renovar el universalismo en clave no socialista, han ido asumiendo compromisos liberales; y los "indecentes", que bajo la influencia del postmodernismo tienden a fracturar el liberalismo a partir de una diferencia heterogénea de carácter generalmente étnico, no de clase. Así pues, dado el carácter hegemónico del capitalismo como forma de organización social "incontestada", la sola defensa de los valores liberales está constituyendo el trabajo más arduo de los liberales. Es aquí, en este espacio crítico, donde se forja el liberalismo cultural.

$\mathrm{Si}$ el liberalismo es una ideología heterogénea cuyos efectos se concretan mayoritariamente en la contracción y homogeneización del espacio político, el liberalismo cultural es una ramificación del mismo, también heterogénea, que se esfuerza en romper con esta consecuencia de oclusión a partir de una serie de virtudes: desarrolla con frecuencia (aunque no siempre) desde el liberalismo más productivo y actualizado (liberalismo contracturalista de Rawls) una forma avanzada y moderna de afrontar la diferencia; propone una forma honesta de superar las clásicas discusiones entre el liberalismo y el comunitarismo; se esfuerza por integrar otras disciplinas científicas en los marcos de interpretación liberales convencionales (integración de conocimientos desde la antropología, la sociología y la historia); tiene una vocación de desarrollo de ese contractualismo a partir del desarrollo de una ciudadanía diferenciada. Aunque el espacio del liberalismo cultural, en sus innumerables perspectivas y discusiones, es inabordable, sí pensamos en tres de los trabajos de referencia más connotados para abordar la discusión con ellos. Estos trabajos son los de Bian Barry, J.T. Levi y Will Kymlicka. Las diferencias entre ellos son notables: Barry y Kymlicka son rawlsianos con distintos grados de compromiso; Levi y Kymlicka son en sus exposiciones más liberal culturalistas que el primero; y, a nuestro juicio, los trabajos de Barry y Levi tienen consecuencias mucho más conservadoras que las de Kymlicka. La elección de estos tres representantes tiene que ver con varios argumentos: su calidad y claridad expositiva, el carácter masivo de su difusión intelectual (no hay artículo sobre el multiculturalismo que no los cite), y su sistemática forma de afrontar el problema de los límites de la identidad y la diferencia en un marco de regulación social liberal.

\footnotetext{
${ }^{5}$ Este tipo de razonamiento aparece explícitamente desarrollado en el último trabajo de Brian Barry, (2001: 3-15).
} 
A un liberal cultural se le detecta porque rompe con el núcleo duro del liberalismo que consiste en ligar el desarrollo del derecho al sujeto individualizado. Como ya sugerimos, los liberales tienden a desconfiar del Derecho por ser un elemento regulador de las vidas de las personas que interfiere en sus formas vitales de ser y actuar. Pero paradójicamente, como dice F. Ovejero: "[...] la ley, opuesta a la libertad, ha de garantizar esos derechos anteriores a la ley misma; la ley, que interfiere, ha de proteger frente a las interferencias" (Ovejero, 2002: 82). Esta paradoja no resuelta traza una línea fundamental entre los que establecen un reconocimiento del derecho diferenciado ${ }^{6}$ y los que no (los liberales culturalistas frente a los liberales a secas). Aquí, la política de la diferencia (y en algunos casos la autoafirmación étnica) es percibida no necesariamente como amenaza irreductible, sino como un campo de posibilidades del que aprender. El más optimista de ellos, Kymlicka, sitúa el lugar del riesgo en no afrontar nuestra heterogeneidad a partir de políticas igualitaristas insensibles a las diferencias e incapaces de establecer políticas de acomodo o de reconocimiento acordes con los problemas vividos por una ciudadanía que de hecho ya es diferente. En cierto sentido, el liberalismo cultural hace suya la idea del Tribunal Supremo canadiense cuando defiende que "la acomodación de las diferencias constituye la esencia de la verdadera igualdad" (Ibid. p. último cuadro).

Pero vayamos por partes. Quizás de entre los tres intelectuales mencionados sea Barry el que más restricciones pone a las políticas del reconocimiento, es decir, el que se muestra más liberal en estado puro. En este sentido, puede leerse su trabajo como la transición entre el liberalismo y el liberalismo culturalista. Para él las políticas de la diferencia son concebidas como un peligro porque se proyectan como un autoafirmación étnica y un "nacionalismo estridente" (Barry, 2001: 3). De hecho, es ese fantasma y no el del marxismo el que parece recorrer Occidente en nuestros días. En el fondo existe una sospecha saturada de inquietud en sus reflexiones. El surgimiento de nuevos movimientos sociales que tienen por objetivo erosionar la credibilidad del sistema y las libertades conseguidas ha transformado sus ropajes para adaptarse a los nuevos tiempos; se ha producido un desplazamiento de las politizaciones de clase a las culturales o étnicas y esto ha generado un escenario de reflexión crítica que favorece el conservadurismo.

\footnotetext{
${ }^{6}$ Como expresa convenientemente Kymlicka (1996: 71), este derecho diferenciado no puede ser asimilado necesariamente a derechos colectivos, puesto que existen derechos de diferencia que son ejercidos desde los sujetos individuales exclusivamente. La expresión derechos colectivos sugiere una falsa dicotomía: "Podemos ver ahora por qué el término derechos colectivos resulta de poca ayuda a la hora de describir las diversas formas de ciudadanía diferenciada en función del grupo. El problema es, por una parte, que el término es demasiado amplio y, por otra, que no logra trazar la distinción entre restricciones internas y protecciones externas. Pero un problema más profundo es que dicho término sugiere una falsa dicotomía con los derechos individuales".
} 
Para él la diferencia en la mayor parte de los casos es sinónimo de privilegios o de excepciones legales, lo que al parecer hace retroceder el Derecho a etapas premodernas y conservadoras ${ }^{7}$. La uniformidad de la ley aparece, así, como la conquista más lograda de la modernidad y el lugar desde el que poder construir un concepto de ciudadanía completa. Poner en marcha políticas multiculturales es, por tanto, asumir el fracaso del liberalismo y generar un retroceso tanto de la libertad como de la igualdad. Golpear a la Ilustración se ha convertido para él en el deporte más extendido entre intelectuales de toda condición.

Así las cosas, ¿en qué es, entonces, culturalista Barry?, ¿cómo podemos caracterizarlo dentro de este grupo de liberales culturalistas si desconfia tan fuertemente del principio de la diferencia? A él no le queda más remedio que reconocer en su libro que inevitablemente "existen razones para introducir derechos diferenciados para los grupos con base en la pertenencia a los grupos culturales" (Ibidem: 10). Este principio, aceptado a regañadientes, es el reconocimiento de que el liberalismo necesita incorporar el principio de diferencia si quiere dar respuesta a las injusticias generadas. La exigencia de que tales derechos diferenciados en comunidades diferentes deben ir (porque no suelen hacerlo, según él) acompañados del fomento incondicional y sostenido de la igualdad y la libertad no es más que una última pataleta ${ }^{8}$. Para empezar porque, como recoge la Constitución australiana, las políticas multiculturales también están sometidas a restricciones (lealtad nacional, aceptación de la Constitución y reconocimiento del derecho de otras culturas a expresarse).

Para Barry (Ibidem: 10-15) una política correcta supondría: afirmar los derechos civiles y políticos; desarrollar una acción afirmativa siempre y cuando eso de lo que se carece se defina claramente como algo que falta en términos universales y se establezca con carácter temporal para su superación; reconocer derechos de grupo en el caso de culturas mal situadas para beneficiarse de derechos (esto supone un fracaso del liberalismo); y no renunciar a la importancia del Derecho para pensar tanto la libertad, como el igualitarismo. Como podemos comprobar, la preocupación de Barry por la importancia del concepto de ciudadanía, así como su preocupación porque las políticas de reconocimiento no debiliten las políticas de redistribución, le sitúan en actitud de aceptación escéptica ante la idea de la diferencia. Pero ese escepticismo debe asumir la contradicción de navegar entre la nostalgia imposible de una ciudadanía republicana unitaria y el hecho de que todo ejercicio de la justicia pase por el respeto y la protección de la diferencia entendida como diferencia culturalmente liberal. El que un liberal

\footnotetext{
${ }^{7}$ Según Barry (Ibidem, pp. 3-15), la máxima "divide y gobierna" del multiculturalismo tiende en general a beneficiar al status quo imperante.

${ }^{8}$ Un contraejemplo de compatibilización entre derechos diferenciados y defensa exhaustiva de la libertad y la igualdad no liberal lo encontramos en los trabajos de Nancy Fraser (1997).
} 
RIS

REVISTA INTERNACIONAL DE SOCIOLOGIA

No 37, ENERO-ABRIL, 2004

JOSÉ LUIS CASTILLA VALLEJ0

como él resulte tan enternecedoramente preocupado por la redistribución (al estilo del contractualismo de Rawls) no deja de ser una forma, a nuestro juicio, cínica de representación de las preocupaciones; pues, como veremos, el discurso del propio Rawls no es más que una formulación que, como dice Negri y Hardt $(2003: 32)^{9}$, tiende a generarse a partir de unos principios racionales fundadores que encubren las relaciones de fuerza y dominación que organizan realmente la sociedad, así como a enmascarar un orden de reproducción social basado en el trabajo. Como estos críticos plantean, el trabajo queda literalmente expulsado de la teoría. La preocupación de Barry de que las políticas multiculturales acaben defendiendo el estatus quo no deja de resultar paradójica en un presente en el que el pensamiento liberal o liberal-conservador, si se prefiere, resulta precisamente hegemónico y característico del estatus quo imperante.

Pero el liberalismo cultural más sobresaliente no anda con tantas dudas en su cabeza. El concepto de diferencia es asumido con naturalidad aun reconociendo que cortocircuita aspectos importantes de su propia tradición. Este liberalismo cultural de tono más sociológico nos descubre una forma de hacer ciencia social de un modo más pragmático, más apegada a los problemas reales de las sociedades occidentales contemporáneas. Aunque se les ha criticado con vigor su excesivo tono generalizador, su insensibilidad para con la sociología y los estudios culturales, y su falta de aterrizaje en problemas concretos, lo cierto es que despliega un tono mucho más comprometido con la praxis que el liberalismo convencional. Como dice Ovejero, el meollo del pensamiento único (expresión y concreción histórica y heterogénea del pensamiento liberal) "es normativo y, por ello, resulta inatacable empíricamente de modo concluyente" (Ovejero, 2002: 25). No es un problema de datos a contrastar, sino de postulados a defender. Es por eso que la vocación del liberalismo cultural resulta más productiva, más edificante y menos siniestra que la del liberalismo al que estamos acostumbrados a oir hablar.

Los dos representantes escogidos aquí son Kymlicka y Levi. En ambos el derecho a la diferencia se construye a partir de una preocupación fuerte en torno a las políticas multiculturales. Es curioso el modo en que los liberales (incluidos los liberales culturales) abordan las discusiones sobre el multiculturalismo. Tienden

\footnotetext{
${ }^{9}$ Barry critica a los marxistas que no es sólo la Ilustración la que se volvió insensible a la diferencia, sino también el marxismo y el propio Marx. En ambos casos, lo que se establece, según él, es un ajuste de cuenta con el derecho que tiende a liquidarlo. Desde nuestra perspectiva, lo que se tiende a liquidar no es tanto el derecho como el desarrollo del derecho burgués. Poco puede hablarse de la relación entre el derecho y un nuevo orden social imaginado, porque más bien poco produjo Marx sobre el segundo. En cualquier caso, para una discusión de interés sobre Marx, el derecho y el principio de justicia puede revisarse el debate que ha venido dándose en el marco de la New Left Review desde mediados de los 80. Puede verse Geras (1985).
} 
a partir menos de un diagnóstico crítico de las sociedades modernas y sus consecuencias o reclamos, y más a contestar las diversas políticas multiculturales que se han ido forjando en el propio combate social. Esto no sería significativo si, en voz del propio Kymlicka, no se dijese que el liberalismo cultural no tiene rival intelectual al que enfrentarse ${ }^{10}$. En cualquier caso, el tono con el que uno y otro abordan la discusión sobre las oportunidades y los peligros de la afirmación de la diferencia resultan radicalmente opuestos: mientras que Kymlicka es optimista, pragmático, rawlsiano, afirmador del derecho en general y del derecho diferencial en particular; Levi, con su multiculturalismo del miedo (aunque se entendería mejor si se llamara del riesgo), resulta fuertemente sombrío, pesimista, antropológico y desconfiado del Derecho, porque su tradición no es Kant sino Montesquieu. Entre el vaso medio lleno y el vaso medio vacío quedan representadas dos formas importantes de concreción del liberalismo cultural.

\section{a) Levi o el liberalismo del miedo}

Para Levi no hay nada más aterrador en el mundo moderno que la violencia y crueldad política de los vínculos entre etnicidad y cultura. La cultura es vista como el centro del problema. Ésta no se celebra como expresión de la diversidad, ni se vive como un elemento de enriquecimiento colectivo; más bien es un lobo que anda al acecho de sus nuevas víctimas en cuanto esa diversidad se transforma en resentimiento. Como el objetivo que encara este liberalismo del miedo es prevenir toda crueldad, la estrategia ha de ser "plantear una teoría política y social del multiculturalismo y del nacionalismo que se centre principalmente en los peligros de la violencia, crueldad, humillación política que tan a menudo acompaña al pluralismo étnico y a la política étnica" (Levi, 2003: 29).

No se trata de analizar a los individuos y sus derechos, sino más bien sus peligros. Para el liberalismo del miedo, los derechos no son concebidos únicamente como una garantía de la justicia etnocultural; hay otra forma de mirar el multiculturalismo a partir del análisis concreto de los riesgos de asumir una vida común diferenciada; una vida en común que es entendida por Levi como el lugar de desencuentro por definición, puesto que siempre hay alguien a quien no entendemos plenamente (Ibidem: 52). En el fondo es una mirada desde el desencuentro permanente, en el que es imposible establecer un sistema de derechos compartidos, porque su imposibilidad arranca de la idea de que elaborar un derecho supone partir de los derechos que cada grupo se otorga a sí mismo. Esta filosofia de la "Torre de Babel" trata, a fin de cuentas, y en sus propios términos, de "evitar el mal, más que la búsqueda del bien" (Ibidem: 55).

\footnotetext{
10 " $\mathrm{Ni}$ el republicanismo unitario ni el postmodernismo brindan una clara alternativa al culturalismo liberal", (Kymlicka, 2003).
} 
RIS

REVISTA INTERNACIONAL DE SOCIOLOGIA

№ 37, ENERO-ABRIL, 2004

JOSÉ LUIS CASTLLLA VALLEJO

Este liberalismo cultural es más historicista al situar en el centro de los problemas que aborda el conjunto de injusticias históricas que se arremolinan en el presente. Es, además, fuertemente antropológico al hacer notar la importancia de los elementos simbólicos en los distintos significados culturales, pero esa mirada de lo simbólico no pretende hacer inventario de la diversidad, sino más bien preocuparse por las consecuencias de los desgarros que provoca. De hecho, este aspecto supone un punto de distanciamiento y autocrítica con respecto a su propia tradición liberal, ya que, según él, la despreocupación por lo simbólico por parte del liberalismo (preocupado casi exclusivamente por el derecho y los recursos) ha propiciado el desarrollo de las llamadas políticas del reconocimiento antiliberales que tan de moda se han puesto en los últimos años (léase Iris Marion Young, Charles Taylor). Otro aspecto de este liberalismo cultural es también su pragmatismo; un pragmatismo político, pues lo que está en el centro de su mirada es la resolución o la atenuación de conflictos. Renuncia a una posición estetizada de la cultura y no deja de lamentar las celebraciones de la diferencia que con mucha frecuencia encontramos en los defensores de políticas de reconocimiento antes citadas.

Pero esta forma de representación liberal tiende a agotarse en su propio esfuerzo. El multiculturalismo del miedo no tiene por consecuencia política, y pese a sus intenciones, una posición liberal, sino, más bien, netamente conservadora. El propio Levi lo reconoce cuando, citando a John Kekes, argumenta que cualquier política que coloque la crueldad en primer lugar es conservadora, no liberal, porque tiende a reducir la autonomía de los crueles (Ibidem: 56). A nuestro juicio, esa actitud conservadora lo es en un sentido más profundo del término, pero eso lo veremos más adelante. Ahora revisaremos la posición del liberalismo cultural más optimista, la de Will Kymlicka.

\section{b) Kymlicka, o el liberalismo optimista}

Will Kymlicka es el más destacado y productivo representante del liberalismo cultural. Hasta cierto punto, y dado el nivel de difusión de su trabajo, puede decirse que él (y, como dice Brian Barry, su "panda de conferenciantes" (Barry, 2001: 3-15) es el liberalismo cultural por excelencia. Su engarce con el contractualismo de Rawls —el liberalismo más secundado en comparación con el liberalismo ideológico y el utilitarista (Ovejero, 2002: 141-152) — y su fuerte defensa del derecho de la diferencia para los dos modelos de diversidad que analiza (minorías nacionales y los inmigrantes ${ }^{11}$ ) lo convierten en un referente fundamental para el desarrollo de la teoría liberal contemporánea.

\footnotetext{
"Kymlika diferencia tres grupos fundamentales: inmigrantes (aquellos recién llegados a un país que son legalmente admitidos y tienen derecho a obtener la ciudadania); trabajadores invitados o inmigrantes ilegales (no tienen derecho a convertirse en ciudadanos, pese a que en algunos casos
} 
El concepto de diversidad en Kymlicka está asociado a la idea misma de minorías. De esta manera, el imaginario construido de multiculturalismo está preñado de una vocación de protección de un sujeto débil y expuesto por disminuido económica, política y socialmente. Pero la mirada de Kymlicka no es simplemente paternal; capta con agilidad que, en el plano de discusión del Derecho contemporáneo, estas diferencias suponen un desafío contumaz a las tradiciones políticas occidentales. En cierto sentido, hace un poco suya aquella idea de Foucault de que las fronteras nos enseñan más de nosotros mismos de lo que imaginamos ${ }^{12}$.

La cultura para Kymlicka no es una amenaza irreductible, sino más bien un hecho, un factum de la propia realidad con el que tenemos que lidiar. Él se deshace del conjunto de postulados liberales convencionales que, estableciendo vínculos entre cultura, etnicidad y nacionalismo, gustan de hacer catalogaciones como las de Ignatieff (Kymlicka, 2003: 38) - cuando diferencia erróneamente entre nacionalismos cívicos y nacionalismos étnicos-, o conciben el desarrollo del derecho diferenciado como una amenaza contra los principios liberales de autonomía, libertad e igualdad. En este sentido, Kymlicka comprende que la autonomía es un concepto vacío si no se parte de la propia idea de comunidad. Piensa con Dworkin que "nuestra cultura no sólo nos proporciona opciones, sino que también nos proporciona las pautas mediante las cuales identificar el valor de la experiencia" (Ibidem: 120). Existe, pues, relación entre la estima de la autoidentificación y la estima colectiva de la comunidad a la que se pertenece. El concepto de cultura societal como "una cultura concentrada en un territorio, centrado en torno a una lengua compartida y utilizada por una amplia gama de instituciones societales, tanto en la vida pública como en la privada" (Ibidem: 39), viene a dar idea del carácter instrumental que kymlicka hace de la cultura en la relación entre Estado, ciudadanía y grupos diferenciados. Este concepto le permite restringir el marco antropológico de la idea de cultura a una discusión netamente politológica y estatista a costa de cercenar el concepto mismo de multiculturalidad.

pueden ser residentes permanentes del Estado); minorías nacionales (grupos que formaban sociedades completas y operativas en su tierra natal histórica antes de verse incorporadas a un Estado mayor). (Kymlicka, 2003: 11-33).

${ }^{12}$ Una sociedad se define mejor por lo que niega que por lo que afirma, decía Foucault. Esta forma de poner en jaque la autoconfianza de la razón ilustrada es, como veremos, un aporte fundamental para la definición del concepto de diferencia. Como comentaba Foucault en relación con los asilos: "...lo importante no es que las cadenas hayan caído cuanto descubrir el mito que ha dado sentido a esa liberación, abriéndola a una razón poblada de temas sociales y morales...".(Foucault, 1995:499) (para una revisión completa del concepto de poder puede consultarse Castilla, 1999). 
Pero Kymlicka no sólo genera un marco de definición conceptual propio, sino que, además, desarrolla cinco puntos de discordia con su propia tradición liberal. Veamos cuáles son:

- El primero es el ya citado reconocimiento del derecho diferenciado (el indicador de ser liberal cultural); es decir, la convicción honesta de que se necesita un desarrollo del Derecho más allá de los derechos civiles y políticos de la ciudadanía individual. Para Kymlicka los derechos de las minorías no pueden subsumirse, por ejemplo, bajo la categoría de derechos humanos. Esto genera como consecuencia que se requiera un estatus especial de acomodo.

- Este desarrollo del Derecho debe ser convenientemente elaborado para que no suponga restricciones de los derechos individuales y pueda servir de complemento a éstos. Aquí se sitúa la importante distinción entre restriçciones internas (derechos contra el impacto de la disensión interna), a las que Kymlicka se opone, y protecciones externas (derechos contra el impacto de las presiones externas), que acepta sin problemas ${ }^{13}$.

- Niega el principio liberal de la neutralidad del Estado. Si bien para los liberales convencionales la libertad negativa expresa el derecho de no intromisión, esta amenaza aparece generalmente vinculada a la presencia del Derecho y del Estado que éste desarrolla. En tal sentido, la exigencia de neutralidad del Estado se configura como una consigna particularmente importante para una sociedad cuya regla fundamental es la libertad libera ${ }^{14}$. Pero esta presunción no es para los liberales culturales más que eso, presunción, pues se constata empíricamente que los Estados son o tienden a ser multiculturales y necesitan de un modelo teórico y empírico de construcción nacional compartida.

- Aquellos liberales que defienden la existencia de un corte real entre el desarrollo del derecho igualitario y el nacionalismo étnico olvidan que "todas las naciones liberales han tenido un pasado iliberal"15 y que, por tanto, distinguir entre sociedades liberales e iliberales para valorarlas con perspectiva histórica es, cuanto menos, equívoco.

\footnotetext{
${ }^{13}$ Es importante aclarar que en este aspecto hay distintas posiciones dentro del liberalismo cultural, pues hay quien acepta las restricciones internas siempre y cuando exista la posibilidad de abandonar el grupo de referencia. Ver, en este sentido, Kymlicka (2003: 36-37).

${ }^{14}$ Puede ser conveniente citar aquí el irónico comentario de Antonio Machado en Juan de Mairena en relación con la libertad y el liberalismo: "La libertad, señores (habla Mairena a sus alumnos), es un problema metafísico. Hay, además, el liberalismo, una invención de los ingleses, gran pueblo de marinos, boxeadores e ironistas". En Machado, A.: Juan de Mairena. Sentencias, donaires, apuntes y recuerdos de un profesor apócrifo 1936, Castalia, Madrid, 1991, pp.51-52.

${ }^{15}$ Esta confrontación entre sociología y liberalismo no deja de ser una construcción abstracta, no sólo porque hay sociólogos liberales, sino porque existen importantes recorridos sociológicos que ponen el acento en la capacidad de los sujetos para construir la realidad. En cualquier caso, y como
} 
- En definitiva, la amenaza y los peligros no están tanto del lado de la erosión de la cultura compartida predominantemente, como de no saber reconocer la múltiple composición de la que estamos constituidos y las injusticias construidas a partir de ese igualitarismo insensible.

A partir de ese ejercicio crítico, el conjunto de reivindicaciones que afloran para dar cuerpo a esa teoría de la construcción nacional, además de seguir un enfoque netamente estatista (Kymlicka sólo parece afrontar el reto de las políticas desde la concepción de una sociedad política responsable, pero desde una sociedad civil inexistente), no parece llegar más allá de una defensa nuevamente abstracta de la igualdad de oportunidades y de una declaración grosera y general de por dónde se debe ir en la construcción nacional. En este sentido expresa Kymlicka cinco propuestas que van más en la línea de valorar la diversidad, mostrar respeto por las identidades y respetar las autonomías individuales. Estas propuestas son (Kymlicka, 2003: 59-61): primera, no tratar de imponer de manera coercitiva una identidad nacional a aquellos que no la comparten; segunda, permitir actividades políticas dirigidas a dar espacio público a un carácter nacional distinto; tercera, tener una definición muy abierta de comunidad nacional; cuarta, manifestar un concepto más débil de la identidad nacional; quinta, no desmantelar las instituciones de autogobierno de otros grupos culturalmente diferenciados.

Se pretende una idea de justicia social que intenta la síntesis entre libertad individual y derecho a una equidad entre los diferentes grupos etnoculturales en el seno de una comunidad política. Pero, a pesar de sus diferencias, en el liberalismo cultural de Kymlicka la justicia social adquiere un lugar parecido al que adquiere en el caso del contractualismo rawlsiano del que se siente deudor. Toda su sensibilidad con respecto a la diferencia acaba en el abrevadero de una de las tesis fuertes del liberalismo clásico, la que defiende que, en última instancia, los individuos han de asumir las consecuencias de sus actos, y no es tarea del Estado proteger a las personas de sus decisiones. Esta idea, que llevada coherentemente obliga al Estado a mitigar el mal no elegido, hace que esta tesis de la responsabilidad, como dice Ovejero (2002: 30), esté fuertemente implicada en políticas de bienestar de amplio calado. Aquí se esconde una fuerte confrontación entre el liberalismo como corriente y la sociología como disciplina, pues ésta nos ha dado muestras notables del carácter determinante de la construcción social de los sujetos (consumos, gustos, hábitos, etc.) y de los márgenes de elección que

signo de contraste, hagamos notar dos iconos reclamados por ambos elementos: para el liberalismo el icono de Robinson Crusoe constituye el referente de aquel estado puro y solitario de un sujeto ideal sin interferencias; el icono para la sociología lo constituye el "pequeño salvaje de Aveirón", la representación de que el individuo sólo es pura animalidad y que la existencia de derechos previos no es más que una gran ilusión absurda. 
tienen los mismos en su diferenciada vida social ${ }^{16}$. En este sentido, las posiciones estructurales de los sujetos dejan mucho menos margen para el uso de una responsabilidad que los liberales tienden a sobreestimar. Un ejemplo notable lo tenemos en las amplias deconstrucciones de la idea liberal de igualdad de oportunidades que se ha producido en la sociología de la educación en las últimas tres décadas. Nunca un concepto tan poco específico y elástico dio tanto que discutir.

El liberalismo cultural se despega así del liberalismo convencional optimista negando la llamada paradoja de Condorcet, aquella que veía en la construcción de una civilización común la caída imparable de las identidades nacionales y el surgimiento de una cultura común compartida universalmente. Su optimismo no pasa por negar la diferencia, sino afirmarla en positivo, porque es la forma en la que diversidad y autonomía individual pueden integrarse de forma efectiva. Pronostica que el mundo que nos espera no es uniforme, sino diverso y en điversificación. En todo caso, en un aspecto puede unificarse y es en el desarrollo del derecho de libertades liberales ya asumidas como definitivas en Occidente. Los principios liberales democráticos, según él, no están puestos afortunadamente en cuestión.

\section{EL LIBERALISMO CULTURAL FRENTE AL MULTICULTURALISMO COMPLEJO}

Partiendo del reconocimiento y respeto que merecen estos trabajo, así como sus intentos desiguales por hacer conciliar la idea de diferencia con las libertades democráticas de las que tan orgullosos se sienten, vamos en este apartado a intentar ver cuáles son los límites de sus teorías y las paradojas en las que incurren. Nos centraremos fundamentalmente en los dos últimos trabajos descritos como referentes principales de lo que se llama el liberalismo cultural, en especial, el de Kymlicka por constituir, a nuestro juicio, la versión más completa y acabada y de más proyección internacional.

Nuestra principal incomodidad corresponde con el concepto mismo de diferencia. Estamos convencidos de que su vinculación a diferencias consideradas minoritarias (minorías nacionales e inmigrantes) pauta el análisis y establece un sesgo nada desdeñable a los trabajos mencionados. La diferencia es entendida como grupo maltratado en un espacio político consolidado y definido con trascendencia histórica y avatares simbólicos desiguales que afectan al presente. Pero

\footnotetext{
${ }^{16}$ Como dice Yael Tamir, también citado por Kymlicka: "la mayoría de los liberales son nacionalistas" (Kyimlicka, 1996: 133-34).
} 
a pesar de ese pasado, la realidad presente es concebida como netamente injusta y proclive a generar desequilibrios. En ese sentido, para el liberalismo cultural la diferencia es real y actual, tanto si se concreta en desigualdades económicas, en ausencia de derechos políticos y sociales o en ausencia de respeto a cualquier comunidad. Al concebir la cultura como cultura societal, la delimitación de la injusticia pasa por resolver los desiguales accesos a la misma, como si las injusticias basadas en lo cultural no fueran más allá del atendimiento a una lengua o la aceptación y respeto a los usos y costumbres de los grupos minoritarios.

Una comprensión amplia del concepto de diferencia no puede tener como único soporte la cultura societal. Esto es así para el liberalismo cultural porque necesita imperiosamente ponerle límites a lo que llama injusticia y a lo que llama diferencia. Lo cierto es que este concepto de diferencia es, con frecuencia, más extenso de lo que siempre imaginamos. De hecho, la antropología y la sociología no cejan en su empeño de romper los límites de nuestro redoblado etnocentrismo cada vez que intentamos comprender una realidad social y cultural a través del principio de justicia y su relación con nuestras libertades. En ese sentido, una política cultural o multicultural que desee proyectarse con sentido teniendo en el horizonte la idea de justicia debe usar un concepto de diferencia fuerte, y no débil como hace Kymlicka.

Pero, seamos claros, ¿qué entendemos por un concepto fuerte de diferencia? Para nosotros, el concepto fuerte de diferencia se encuentra en los trabajos de Michel Foucault ${ }^{17}$. En sus escritos el principio de "desarrollad vuestras legítimas rarezas" se convierte en el núcleo a partir del cual pensar la libertad que tanto respetan los liberales. Para Foucault el respeto a la diferencia pasa no sólo por pensar en las injusticias actuales y reales, sino por escudriñar otras dimensiones en las cuales las categorías se vuelven normalizantes y opresivas. Su filosofía de la sospecha lleva a componer un concepto de diferencia multidimensional a partir del cual realizar una crítica radical de nuestras tradiciones culturales y nuestras instituciones. ¿Cuál es la diferencia de la diferencia foucaultiana ${ }^{18}$. Desde nuestro punto de vista, la diferencia en Foucault es compleja porque se construye desde el interior de cuatro dimensiones:

\footnotetext{
${ }^{17}$ Se hace necesario aclarar en este punto que el concepto de diferencia es de Derrida (différance), y con él hace notar tanto el concepto de diferir, es decir, ser diferente o disímil, como la idea de posponer, retrasar. La dispersión de los significados y la construcción del mismo lenguaje pasa por esta ambivalencia impidiendo el acceso a la verdad profunda de una narrativa. En Foucault esta diferencia aparece no sólo como un pliegue del discurso, sino como una forma en la que el poder produce diferencias normalizándolas.

${ }^{18}$ En este punto hemos de hacer notar que Foucault desarrolla el principio de diferencia a partir de una preocupación por el reconocimiento más que por la redistribución. Este aspecto reconocido por él mismo en numerosas ocasiones vuelve a todas luces incompleto su análisis en esta dimensión.
} 
RIS

REVISTA INTERNACIONAL DE SOCIOLOGIA

No 37, ENERO-ABRIL, 2004

JOSÉ LUIS CASTILLA VALLEJO

- Diferencia desde la precaución con la racionalidad. Por diferencia desde la racionalidad entiende Foucault que las injusticias o la falta de respeto a comportamientos y formas de vida diferenciadas son muy sutiles y simbólicamente complejas. Estas injusticias se ven a menudo atravesadas por procesos de racionalización a través de los discursos y las disposiciones (por supuesto también científicas) que obstruyen cualquier proceso de dignificación de la diferencia pura. De hecho, los conceptos científicos son una forma a veces de excluir, a veces de normalizar, la diferencia y asimilarla al servicio de un patrón racional definido. Por eso la desnormalización constituye un elemento central de las implicaciones políticas de sus conclusiones ${ }^{19}$.

- Diferencia del poder. El poder es pensado de forma que trasciende el derecho y la soberanía. Se ejerce desde innumerables puntos y en el juego de relaciones móviles y no igualitarias. El poder viene de abajo y no hay opción binaria dominantes-dominados, que es como suele pensarse el poder. Además, las relaciones de poder son intencionales y no subjetivas y están sometidas a la lógica de donde hay poder hay resistencia. Aquí el principio de diferencia rompe con las concepciones que la politología suele construir como elemento configurador del orden social. Esta concepción del poder tan aguda supuso en los años 70 que Foucault representara un pensamiento transgresor dentro de la propia izquierda revolucionaria; encarnaba el espíritu más radical de una dialéctica de la modernidad todavía en progreso.

- Diferencia del orden cultural. La fuerza de la identidad como elemento de poder engendra, en lenguaje liberal, restricciones internas, o en lenguaje foucaultiano, mecanismos de regulación que constriñen el desarrollo de la diferencia. Esto supone asumir la paradoja frakfurtiana de que "no existe documento de cultura que no sea a la vez documento de barbarie" (Álvarez, 1996: 5). A partir de ese principio el orden cultural es concebido no sólo como facilitador de una identidad afirmada y creativa, sino como mecanismo de opresión totalitaria. Ambos aspectos, identidad y diferencia, aunque son utilizados como rivales confrontados, constituyen un par indisoluble. Pero lo importante aquí es destacar cómo el peso de la trayectoria histórica engendra redes de pensamiento que posibilitan y restringen a la vez formas de pensamiento. Esto supo recogerlo muy bien $\mathrm{M}$. Foucault de los filósofos de la denominada Filosofía del Concepto ${ }^{20}$.

- Diferencia del orden institucional. Las instituciones son una extensión de la lógica cultural que se analiza. Las formas de ritualización institucional y las

\footnotetext{
${ }^{19}$ Los trabajo de Judith Butler son aleccionadores al respecto y suponen una orientación crítica al liberalismo basado en el derecho fundamental. Ver en este sentido Butler (2001).

${ }^{20}$ Por Filosofia del Concepto entendemos al amplio espectro de intelectuales franceses que van desde Bachelard a Cangüilhem, éste último profesor de Foucault, notablemente preocupados por las transformaciones de los discursos científicos y sus consecuencias para la producción científica.
} 
formas de regulación de los espacios hacen hablar a las instituciones sobre lo que son y sobre lo que hacen. Por eso, desconfiar de ellas no es sólo desconfiar de sus discursos, intenciones y voluntades explícitas, sino desconfiar de su orden, de su codificación y de su subterráneo devenir. Los liberales tienden a creer con demasiada frecuencia que las instituciones hacen lo que dicen que hacen y sirven para los fines que dicen servir.

- Diferencia del resistir. No es posible una resistencia clara sin una experiencia vivida de opresión. En tal sentido, el principio al que Foucault se podría sentir cercano es al de una posición de objetividad subjetivada (o también objetividades encarnadas) ${ }^{21}$ expresada, por ejemplo, por los Queer Studies ${ }^{22}$. El que no hablen en nombre de uno mismo y se dé la voz a los sin voz no sólo es un principio de precaución, sino de respeto a la diferencia reconocida como tal.

Es desde estos márgenes desde los que pensamos con Foucault la diferencia. El problema de un discurso tan disolvente como el suyo es que su voluntad desnormalizadora y sus ansias de libertad menosprecian a menudo aspectos importantes de nuestras instituciones y, sobre todo, y más grave, prescinde del Derecho como elemento sospechoso de normalización social. Pero, dejando a un lado esa retórica, la construcción de esa diferencia compleja parece vital para la búsqueda de un principio de justicia honesto capaz de engendrar en su seno una política multicultural compleja. El liberalismo cultural y su principio de diferencia, tal y como lo expresa Kymlicka, no va más allá de un reconocimiento explícito de oportunidad cultural. Para garantizar esa oportunidad, el derecho diferenciado pretende ser el elemento a partir del cual resolver el problema. Pero como saben los antropológos y sociólogos, los aspectos simbólicos tienen trascendencias históricas imprevisibles; como decía Marx, los muertos están entre los vivos. Una diferencia que sólo contempla la injusticia como oportunidad y no como posible generadora de resentimiento, oculta un aspecto fundamental de la problemática, del concepto de cultura. En ese sentido, Levi se muestra mucho más sensible,

\footnotetext{
${ }^{21}$ Jorge Arditi en un excelente prólogo a la obra de Donna J. Harawayn (1995: 14-15) comenta en relación con esto que la crítica de la razón centrada en el sujeto no sucumbe ante la falta de esperanzas por dos razones: "Primero, porque al negar la inocencia de su lectura puede hacerse auténticamente comprometida, tanto política como moralmente. Pero, también, porque al negar su inocencia y reconocer la parcialidad de su propia visión puede evitar el impulso que ha pervertido toda comprensión a través de nuestra historia (la historia del Occidente, escrita por la voz única y omnívora del Hombre Blanco...): el impulso para esencializar, para transformar toda cosa en la imagen de uno mismo".

${ }^{22}$ Los Queer Studies constituye un marco de trabajo multidisciplinario integrado como regionalidad de los Cultural Studies. La erosión de la identidades unitarias a través de la resignificación de lo "raro" y lo "extraño" en afirmaciones provocadoras a través de los "performances" dibujan un combate social en torno a la otredad de características muy interesantes. Para un lectura inicial de estos estudios puede revisarse el trabajo de Kosofsky (1998).
} 
R I S

REVISTA INTERNACIONAL DE SOCIOLOCIA

№ 37, ENERO-ABRIL, 2004

JOSÉ LUIS CASTILLA VALLEJO

aunque tampoco escoge el camino que le abre la puerta a la desnormalización ${ }^{23}$. Por eso los liberales no entienden, ni entenderán jamás, conceptos como los de neocolonización u opresión cultural transgeneracional. Por eso cuando autores como Brian Barry hablan de acción afirmativa lo suscriben a algo concreto, medible, objetivable y de duración transitoria.

Los liberales culturalistas no entienden que la opresión es multidimensional, que atraviesa a las diversas racionalidades que construimos incluso a través de la ciencia, que tiende a concebir un principio de diferencia ingenuo con respecto a un poder que tiende a ocultar formas importantes de opresión, que elude el carácter histórico de nuestra lógica cultural interna, que subestima el poder fáctico y ritual de unas instituciones que hacen más de lo que dicen hacer $\mathrm{y}$, finalmente, que desprecia la voz de parte de los afectados al no atender el principio de precaución de dar voz a los dañados.

Este último aspecto es relevante para el análisis de Kymlicka, porque en todo momento parece que es el Estado el único capaz de intervenir y regular el desencuentro cultural. La sociedad civil no asoma por ningún lado, ni es sujeto activo en la realización u oportunidad de hacer la política ${ }^{24}$. Como la matriz es el contracturalismo de Rawls y la hegemonía del Derecho es total, la sociedad civil es sólo el lugar en el que se establecen los desencuentros, pero esos desencuentros son netamente culturales y en poco se relacionan con los procesos de modernización contradictorios que vivimos (sobre esto hablaremos más adelante). En ese sentido, se le podría decir a Kymlicka que el Derecho es sólo una dimensión de la regulación social y que en todo caso, como dice Habermas (2001: 15), "las instituciones de libertad constitucional sólo valen lo que la población hace de ellas".

De forma un tanto arrogante, Kymlicka dice no encontrar rival al liberalismo cultural y a sus propuestas multiculturalistas construidas a partir de su principio de diferencia. Al parecer, ni el republicanismo unitario (insensible al drama que aquí se representa) ni un postmodernismo defensor de una ciu-

\footnotetext{
${ }^{23}$ Para Levi (2003: 298), su concepto de diferencia extiende su crítica dentro del campo liberal para poder pensarla sin necesidad de acudir a las tres tradiciones liberales más notorias: la economía neoclásica, la jusrisprudencia angloamericana y la teoría neokantiana de los derechos. La separación de este macrocosmos liberal le sitúa en un punto de vista liberal distinto, con un concepto de diferencia más antropológico, pero en ningún caso llega a atravesar la barrera de la crítica de la racionalidad. Ver, en ese sentido, Levi (2003: 298).

${ }^{24}$ Bien es cierto que en su libro La política vernácula aclara que "[...] sin el fomento de la ciudadanía, el multicultuarlismo es, casi invariablemente, una receta para la exclusión y una forma de racionalizarla", pero es justamente eso, racionalizarla y estatalizarla, lo que hace en su razonamiento teórico; sólo así puede explicarse lo sobredimensionado de la figura del Estado frente a la sociedad civil y, lo que es más importante, la carencia de análisis sobre un diagnóstico de la ciudadanía occidental. Este tipo de cuestiones no suelen aparecer de forma sistemáticamente estudiadas, de tal manera que lo que él llama principios liberales democráticos o democracia deliberativa acaban siendo principios sostenedores, pero convenientemente situados al margen de cualquier discusión (Kymlicka, 2003: 210).
} 
dadanía radical parecen estar a la altura de las circunstancias (lo que es lo mismo que decir a su altura). Los dos argumentos fuertes que sostienen esta afirmación son: primero, el carácter abstracto y/o metateórico del pensamiento postmoderno (por lo visto, no aterriza lo suficiente); y, segundo, un juicio de valor y expectativa, la justicia liberal es más prometedora. El primero es un juicio que no se sostiene por dos razones: porque el pensamiento postmoderno tiene concreción en áreas de las ciencias sociales muy concretas (pensemos en toda la sociología, politología, antropología e historia construida desde el postmodernismo en las últimas décadas); y porque el pensamiento postmoderno ha nutrido y sigue nutriendo el pensamiento en diversos movimientos sociales y colectividades sometidas a condiciones de opresión en función de la diferencia (gays, lesbianas, grupos étnicos, comunidades religiosas, colectivos feministas, ecologistas, etc.).

En cuanto a la prometedora justicia liberal, debemos recordar que ni en él sensible liberalismo cultural encontramos algo más sólido que una igualdad de oportunidades (de acceso). Como dice McPherson la igualdad de oportunidades puede significar muchas cosas a la vez: "[...] un derecho igual a una vida plenamente humana para todos $[\ldots .$.$] o un derecho igual a entrar en la carrera competitiva por$ obtener más para sí mismo"(Torres, 2001, citando a McPherson). Dada la defensa liberal de las actuales formas de modernización, cabe pensar que esa igualdad de oportunidades elástica se acerca más a la segunda que a la primera dimensión, con lo que puede concluirse que aunque los liberales culturales contemplan un concepto de diferencia que abarca tanto la redistribución como el reconocimiento, su dimensión culturalista y su componente liberal acaban sacrificando la cuestión de la redistribución hasta nuevo aviso.

De nada nos sirve que Kymlicka descubra coordenadas próximas entre ambos pensamientos cuando se equipara la erosión de los esencialismos identitarios postmodernos a las restricciones liberales internas, o se asume que la crítica antiimperialista de los postmodernos es una retórica próxima a las críticas del liberalismo cultural que defiende las protecciones externas. Y no nos sirven porque en el liberalismo cultural no existe la pieza que engarza ambos aspectos. No existe un análisis crítico de la modernidad que ponga en jaque las estructuras mismas de desigualdad que genera el capitalismo y la globalización (recordemos a Grossberg cuando nos enseñaba cómo "la globalización es una máquina estratificante que opera no sólo para borrar las diferencias, sino también para reordenarlas a fin de producir nuevas estratificaciones" ${ }^{25}$ ).

\footnotetext{
${ }^{25}$ Citado en Canclini (1999: 169). Este aspecto nos revela cómo la división social del trabajo constituye un eje importante e imprescindible para pensar el multiculturalismo complejo.
} 
Pero no es sólo la ausencia de una crítica de la modernidad lo que percibimos ${ }^{26}$; el asunto es aún más grave. No existe una teoría política del Estado de concreción histórica capaz de hacer frente a los retos de precisar la diferencia como acontecimiento sociológico. Como sucede con Rawls, y como comentan Negri y Hardt, los principios fundadores no sólo encubren las relaciones de fuerza y dominación que organizan realmente la sociedad, sino que tampoco parten de una elección históricamente situada de un principio filosófico sin contexto (Negri, 2003: 37). El trabajo, la desigualdad de la renta, los procesos de control político del Estado, la definición de los sistemas de bienestar, el Estado de Bienestar contemporáneo es, en general, el gran desaparecido en una teoría que se toma el esfuerzo de debatir en torno a los principios de justicia a partir de la incorporación de una diferencia calculada. Un multiculturalismo complejo que se tome en serio el problema de la justicia no puede usurpar una definición sociohistórica del Estado de Bienestar. De hecho, las políticas multiculturales que son a menudo tan debatidas y cuestionadas no son las únicas que afectan a la multiculturalidad; en el fondo, todo el desarrollo del Derecho no es más que una forma de regular y gestionar las identidades y las diferencias. Todas las políticas son multiculturales.

Ésta quizás sea la idea matriz para pensar en un multiculturalismo complejo. Tal y como lo concebimos aquí, un multiculturalismo complejo se define, en: primer lugar, por un desarrollo del concepto de diferencia amplio; un principio de diferencia que atraviese transversalmente todas las dimensiones reales y simbólicas de los sujetos, pero que limite la retórica fuertemente erosiva del esencialismo de las identidades y la desnormalización que algunos postmodernos han proyectado ${ }^{27}$; y que, además, haga suya la idea de Gitlin de una ciudadanía multicultural que cultive "el espíritu de la solidaridad a través de las líneas de diferencias" (Torres, 2001: 275). Un multiculturalismo complejo está obligado a definir los límites en los que enmarca el Estado de Bienestar y la modernización, que para nuestro caso pueden resumirse en dos objetivos precisos y complementarios ${ }^{28}$ : la necesidad, por

\footnotetext{
${ }^{26}$ Por ejercicio crítico de la modernidad entendemos lo que ha sido consustancial a la propia modernidad, la descrita por la Escuela de Frankfurt como la dialéctica de la modernidad. Una dialéctica que no supone otra cosa que la autocrítica reafirmada de una racionalidad que busca la emancipación del sujeto. En tal sentido, la postmodernidad no es solamente "el deporte de tundir la Ilustración" (como cita Brian Barry), sino más bien hacer del espíritu ilustrado la forja de la autocrítica. Cómo esa autocrítica resulte de dolorosa para algunos es harina de otro costal (Barry, 2001: 5).

${ }^{27} \mathrm{El}$ problema de las retóricas desnormalizadoras es que son críticas que se pueden extender hasta el infinito y son a todas luces autorreferenciales. Es en el fondo la idea de que toda identidad es poder opresivo, lo que autolimita la capacidad de resistencia de los propios grupos humanos que se resisten a la normalización. Esta paradoja aparece bien expresada en el movimiento Queer. La identidad con frecuencia es un poder o contrapoder imprescindible.

${ }^{28}$ Seguiremos aquí el trabajo de J. Rodríguez (2001).
} 
un lado, de crear y recrear constantemente las condiciones económicas, sociales y políticas adecuadas para la acumulación creciente de capital; y, por otro, la necesidad de organizar el malestar social de las clases subalternas generado por el propio desarrollo del capitalismo. Lamentablemente, muchos multiculturalismos críticos fracasan en mantener una posición equilibrada entre los problemas de redistribución y los problemas de reconocimiento, poniendo el acento más en lo segundo que en lo primero, lo que expulsa al problema de la desigualdad económica del concepto de diferencia ${ }^{29}$.

Un multiculturalismo complejo debe ser flexible en sus planteamientos, pero en ningún caso ambiguo. Bien es cierto que la complejidad de lo simbólico y la sofisticación de las narrativas establecen incertidumbres con respecto a los resentimientos; al fin y al cabo, muchos de éstos se construyen a partir de la adhesión a una epistemología perspectivista o también denominada del "punto de vista". Ello nos lleva a tomar precauciones notables sobre las políticas a desarrollar para respetar la diferencia y no generar dolor. En cualquier caso, seamos claros, lo simbólico es fuertemente ambiguo por definición ${ }^{30}$.

Se suele decir que las políticas multiculturalistas siguen una estrategia de escisión perpetua, de divide y vencerás. Situar la solidaridad en el corazón del multiculturalismo es enmarcar en lugar privilegiado el principio francfurtiano que exige mostrar sensibilidad a toda forma de sufrimiento no estrictamente necesario. Pensar a partir de lo que nos une parece ser tan importante como pensar aquello que nos diferencia. Es en esa dialéctica en la que muchos movimientos sociales trabajan articulando a la vez, y no de forma contradictoria, la exigencia de un derecho diferenciado y la política de no normalización de la diferencia. Así las cosas, la representación de lo social como la paz perpetua deseada por los liberales es suplantada por un enfrentamiento entre grupos que aparece como inevitable; pero reconducible hacia aquellos aspectos que nos vinculan (tradiciones, territorios, experiencias, instituciones compartidas, etc.).

De todas formas, el multiculturalismo complejo que hasta aquí estamos pensando es un multiculturalismo que tiende a pensar la diferencia como ejercicio

\footnotetext{
${ }^{29}$ En ese sentido pueden verse las críticas que desarrolla Peter McLaren a la llamada "pedagogía crítica": "la pedagogía crítica se ha vuelto tan totalmente psicologizada, tan liberalmente humanizada, tan tecnologizada y tan postmodernizada conceptualmente, que su actual relación con luchas de liberación más amplias parece severamente atenuada si no es que fatalmente terminada [...] ha sido ampliamente domesticado". En Torres, (2001: 186).

${ }^{30}$ Hagamos notar aquí que muchas diferencias históricamente construidas generadoras de identidad parten de injusticias configuradas antaño, y respetarlas puede suponer reforzar los mecanismos de opresión. En tal sentido, la crítica a la ambigüedad del multiculturalismo crítico debe atemperarse porque lo que es ambiguo en sí mismo son los significados y los sentidos e interpretaciones que damos a una realidad necesariamente compleja.
} 
del poder y de la desigualdad. En realidad la diferencia no tiene por qué estar asociada al poder de forma inevitable. Como nos enseña Gitlin:

"[...] que las diferencias se reducen a relaciones de poder, es ostensiblemente falso (los rusos perciben que los africanos son "diferentes", pero no necesariamente porque tengan poder sobre los africanos, o porque éstos tengan poder sobre ellos), [...] que las diferencias crean automáticamente una relación de poder, es ostensiblemente falso (los kurdos y los tutsis son diferentes, y entre ellos apenas hay relaciones, si acaso las hay). Si significa que las diferencias sólo crean unas relaciones de poder, es ostensiblemente falso (si me gustan los raps de Sister Souljah, no es porque ella tenga el poder de obligarme a comprar su disco compacto). Si significa que no hay relaciones de poder sin diferencias, resulta tautológica [...]" (Torres, 2001: 270-271).

Pero que el poder, como ejercicio generador de injusticia, y la diferencia no sean sinónimos no significa que tal vínculo no siga siendo el problema central de nuestras sociedades. La necesidad de articular el derecho y la desnormalización de la diferencia son los retos de una respuesta multiculturalista compleja en el marco histórico de un análisis sobre tres dimensiones fundamentales de la vida social:

a) Una ciudadanía cada vez más erosionada no sólo desde el ámbito del desarrollo de los derechos económicos y sociales (a través del impacto de políticas neoliberales en el marco generalizado de globalización), sino también desde la erosión manifiesta de derechos políticos y civiles a partir de los atentados del 2001 en EE.UU. (resistencias a la configuración de instancias internacionales de justicia, vulneración de derechos humanos básicos, etc.). Pareciera, siguiendo a Negri y Hardt, como si el Estado fagocitara a la sociedad civil: "¡No se ha extinguido el Estado, sino la sociedad civil!” (Negri, 2003: 82).

b) Una democracia inhóspita ${ }^{31}$, volcada a un sufragismo que no se hace demasiadas preguntas inconvenientes sobre la independencia de los poderes, la configuración de las opiniones públicas, la concentración y control de los medios de comunicación de masas, la financiación de los partidos políticos, etc. Una democracia de competencia que presume de seguir su ideario liberal más estricto: aquél que exige contemplar a los individuos como homo oeconomicus, estar diseñada para funcionar sin virtud alguna y regulada para entender la política como metáfora del mercado del voto (una oferta potencial programática para cada demanda).

\footnotetext{
${ }^{31}$ Recogemos aquí el espíritu del libro de Ovejero (2002).
} 
c) Un Estado de Bienestar fragmentado (Rodríguez, 2001) con una quiebra de las políticas de igualdad universal (las clases medias privatizan sus consumos de servicios por la baja calidad de las asistencias estatales) y reclaman como contrapartidá menos impuestos; el bienestar se va reorientando así hacia una política de desresponsabilidad en la protección dirigiéndose a asistir a los pobres y excluidos que demuestren serlo; una idea de igualdad de oportunidades cada vez más empequeñecida; y una concepción pluralista del bienestar en el que la atención de cualquier naturaleza puede ser atendida por cuatro sectores diferenciados: el oficial, el comercial, el voluntario y el informal. Este pluralismo con tono emancipante procedente del Estado benefactor oculta el terrible hecho de que las tres últimas instancias son incapaces, a todas luces, de dar respuesta a las demandas de la sociedad en su conjunto. Otro efecto añadido es el ejercicio despolitizador del proceso de formación de políticas públicas y el intento de definir las políticas como el territorio de los expertos (Young, 2000: 23).

Es vital comprender este contexto para hacer de la lucha por la justicia multicultural un elemento complejo. El liberalismo cultural queda a años luz de tal necesidad y cumple de forma poco convincente la complejidad del concepto de justicia. Sus ausencias, como sus presencias, están atravesadas por una dialéctica de la ilustración (o autocrítica) limitada. Abordar el problema de la diferencia sin tocar las contradicciones de la modernidad conduce a pensar, como lo hace Levi, que todos los males son engendrados por el vínculo entre etnicidad y movimientos colectivos. Si ese fuera el único problema, la modernización hace tiempo que habría acabado con él. El meollo de la cuestión es que la modernización genera procesos contradictorios, estratificantes y, en general, profundamente injustos. No asumir esa realidad es hacer de la cultura un nuevo fetiche, esta vez para conducir el análisis de la misma al abrevadero de la reproducción de un orden social injusto que pretende con su retórica enseñarnos que el Derecho y la sensibilidad nos convencerán de que "todo va mejor en el menos malo de los mundos posibles". Dejamos de lado un aspecto central que no hemos comentado del multiculturalismo complejo: la necesidad de una pulsión fundamental, la de la utopía (no lugar) sin la cual todo pensamiento convierte en imposible el movimiento de sus aspiraciones.

\section{CONCLUSIONES}

Hace algún tiempo que Moan Rao (2002: 91) en un informe mundial sobre la cultura de la UNESCO afirmaba que el liberalismo económico tiende a considerar la cultura o bien como epifenómeno deseñable de la economía, o bien como un territorio sobre el cual se ejercen opciones individuales. Esto que puede ser 
RIS

REVISTA INTERNACIONAL DE SOCIOLOCIA

№ 37, ENERO-ABRIL, 2004

JOSÉ LUIS CASTILLA VALLEJO

cierto para el liberalismo económico ha dejado de ser realidad para el liberalismo cultural. La cultura adquiere con esta corriente un protagonismo proverbial que ni en el liberalismo a secas consigue lograr. Pero este protagonismo, como hemos visto, al partir de un concepto de cultura pragmático o mejor operativo (cultura societal) convierte el concepto de diferencia en una premisa autolimitante del problema de la desigualdad y la injusticia. La cultura es comunidad intergeneracional, territorio, lengua e historia específica, dejando de lado un concepto pleno de multiculturalidad que incluyera estilos de vida grupal, movimientos sociales y asociaciones voluntarias que están suponiendo para la cultura democrática formal occidental un desafío también incuestionable.

Los derechos de autogobierno, los derechos poliétnicos y los derechos especiales de representación no son más que un primer escalón del gran desafío de la multiculturalidad. Dentro del liberalismo cultural, Levi destaca también como importantes los que tienen que ver con las peticiones simbólicas (denominaciones, enseñanza de la historia, etc.), con el reconocimiento del código legal tradicional (derechos de tierra indígenas, derecho familiar tradicional, etc.), con las exenciones de leyes (leyes de caza, formas de escolarización, etc.) y con las ayudas específicas (papeletas multilingües, acciones afirmativas, etc.). En el otro extremo del abanico, y reivindicando una mirada distinta sobre los problemas de la diferencia, justicia y desigualdad, encontramos a los postmodernos de izquierdas y, en medida nada despreciable también, a los postmodernos conservadores. Todos éstos parten de un concepto de cultura y de multiculturalismo más abierto en el que incluyen la desnormalización y la erosión del Derecho dentro de sus reivindicaciones sobre el respeto a la diferencia.

En tal sentido, estamos convencidos de que una teoría crítica moderna en torno a la diferencia debe seguir los dos caminos tanto en su andadura de la crítica de los supuestos sociales de las injusticias, como de sus respuestas activas a sus consecuencias. La ofensiva en el Derecho resulta, pues, tan vital como la mirada desde la desnormalización. Si se pone el acento sólo en la primera, se tenderá a reforzar con la legitimidad de los discursos oficiales (incluida la ciencia) una visión etnocéntrica de los grupos diversos ${ }^{32}$. Y, por otro lado, si renunciamos a

\footnotetext{
32 Siguiendo a Eva Patricia Gil en un trabajo en el que explica la crítica de Butler a la naturalización de la dualidad sexo y género: "[...] las mismas categorias sociales que te subordinan al mismo tiempo te producen, es que "el poder jurídico inevitablemente produce lo que afirma sólo representar (...) De hecho, la ley produce y luego oculta la noción de "un sujeto anterior a la ley". El poder jurídico produce la ilusión de este "sujeto anterior a la ley", que funciona como pieza clave en el dispositivo reproductor de las mismas relaciones de poder, y que es característica del liberalismo ya que, al presuponer un "antes" de lo social y lo jurídico, se instaura la imagen de la sociedad como aquel conjunto de personas que "consienten libremente ser gobernadas y, con ello, constituyen la legitimidad del contrato social". Es justamente esta lógica de "sujeto anterior a la ley la que nos hace confundir la idea de sujeto constituido por el discurso con la idea de sujeto determinado por el discurso, y nos impide ver la concepción de un sujeto agente si no es en forma de una contradicción".
} 
la lucha por un Derecho diferenciado, pero de espíritu igualitario, lo que es lo mismo que renunciar a cualquier forma de identidad regulada a través del Estado, se perderá un tiempo precioso para la conquista de nuevos territorios y distraerá a la izquierda intelectual en un combate ridículo contra los departamentos universitarios no afines. Buena parte del combate en torno a las políticas Queer son interesantes en este sentido.

Esta compensación se hace tanto más necesaria cuando nos damos cuenta de que las políticas multiculturales están, por su complejidad, permanentemente en jaque en virtud de la denominada "paradoja de la vulnerabilidad cultural" (Kymlicka, 2003: 52), que no es otra que el efecto generado a partir del intento de resolver una vulnerabilidad primaria. Cierto es que en los trabajos de Levi encontramos un análisis simbólico del multiculturalismo que escapa al Derecho, pero no basta con escapar al Derecho para incorporar el principio de desnormalización en la política multicultural. Se hace, pues, necesario comprender algo esencial y es que la esfera de lo simbólico no es puro constructivismo, que el peso de la estructura socio-cultural deviene históricamente en formas de opresión encubiertas a modo de formas de racionalidad, y no sólo en los significados inmediatos de nuestra vida social.

Siendo la tesis fuerte de Kymlicka la idea de que la modernidad se comprende como libertad de elección individual en un marco culturalmente estructurado, lo que no queda nada claro es la relación entre esta modernidad y los procesos de modernización estructurados a partir de la globalización neoliberal. ¿Estamos construyendo un mundo en el que todos podemos elegir aspectos sustanciales de nuestras vidas? La respuesta es no. Parece, pues, urgente solicitarles a los liberales culturales un ejercicio crítico de la modernización y de las consecuencias contradictorias que tienen los procesos sociales a escala internacional, pues no resulta comprensible la tesis de la elección con los procesos de descomposición nacional que viven muchos países, provocados por las enormes concentraciones de la riqueza a escala internacional, por el oligopolio del control de los flujos financieros y la terrible división social-internacional del trabajo.

Visto con un poco de perspectiva, existe una curiosa vinculación entre el liberalismo cultural como propuesta liberal y la retórica de un Estado de Bienestar fragmentario. En ninguno de los dos casos se va al núcleo de la contradicción (el conflicto captial-trabajo en el segundo, y el conflicto división internacional del trabajo para el caso de los inmigrantes, y hegemonía de un nacionalismo liberal que no tolera la escisión de una minoría étnica autodeterminada en el caso de las minorías nacionales); lo que se hace más bien es establecer estrategias para atenuar la contradicción. En el caso del Estado de Bienestar, el concepto clave es "empleabilidad" 33 , es decir, que nadie quede fuera del circuito excluido de los

${ }^{33}$ Citado en Rodriguez, $(2001,259)$. 
flujos regulados por la vida social y económica (Tony Blair: "la mejor garantía de cohesión social es el empleo") (Ibidem, p. 278). Para el caso del liberalismo cultural, la estrategia es también no generar un gueto que pueda poner en cuestión el carácter liberal de las sociedades occidentales; la diferencia debe ser atendida por riesgo a provocar exclusión social y económica. Así pues, la empleabilidad es a la lucha de clases lo que el derecho diferenciado es a la lógica liberal de la lucha cultural. De esta manera quizá comprenderemos por qué en este inicio de milenio al capitalismo tardomoderno se le considera sobre todas las cosas, y no sólo desde el ámbito de la sociología del trabajo, un "capitalismo flexible".

\section{REFERENCIAS BIBLIOGRÁFICAS}

ÁLVAREZ, J. (1996), Michael Foucoult: verdad, poder, subjetividad. La modernidad cuestionada, Madrid, Ediciones pedagógicas.

BARRY, B. (2001), Culture and Equality, Londres, Blackwell.

BUTLER, J. (2001), Mecanismo psíquicos de poder, Madrid, Cátedra.

CANCLINI, N.G. (1999), "Opciones de políticas culturales en el marco de la globalización”, en VV.AA., Informe mundial sobre la cultura. Cultura, creatividad y mercados, Madrid, UNESCO/ Acento.

CASTILLA, J.L. (1999), Análisis del poder en Michel Foucault, La Laguna, Servicio de Publicaciones, Universidad de La Laguna.

FOUCAULT, M. (1995), Histoire de la folie à l'âge classique, Gallimard, París.

FRASER, N. (1997), Iustitia interrupta. Reflexiones criticas desde la posición "postsocialista", Colombia, Universidad de los Andes/Siglo del hombre editores.

GERAS, N. (1985), "The Controversy about Marx and Justice", New Left Review, n 150.

GIL, E.P. (2002), “¿Porqué le llaman género cuando quieren decir sexo?: una aproximación a la teoría de la perfomidad de Judith Butler", Athenea Digital, $\mathrm{n}^{\circ} 2$.

HARAWAY, D.J. (1995), Ciencia, cyborgs y mujeres. La reinvención de la naturaleza, Madrid, Cátedra.

KOSOFSKY, E. (1998), Epistemologia del anuario, Barcelona, Ediciones de la tempestad.

KYMLICKA, W. (1996), Ciudadania multicultural, Barcelona, Paidós.

(2003), La política vernácula. Nacionalismo, multiculturalismo y ciudadania, Barcelona, Paidós.

LEVI, J.T. (2003), El multiculturalismo del miedo, Madrid, Tecnos. 
MOAN RAO, J. (1999), "Cultura y desarrollo económico", en VV.AA., Informe mundial sobre la cultura. Cultura, creatividad y mercados, Madrid, UNESCO/Acento.

NEGRI. A. y M. HARDT (2003), El trabajo de Dionisos, Madrid, Akal.

OVEJERO, F. (2002), La libertad inhóspita. Modelos humanos y democracia liberal, Barcelona, Paidós.

RÓDENAS, P. (1992), "Identidad de la política. Una cartografia de las filosofias políticas tardomodernas", Laguna. Revista de filosofia, $\mathrm{n}^{\circ} 1$.

RODRÍGUEZ, J. (2001), Capitalismo flexible y Estado de Bienestar, Granada, Comares.

TORRES, C.A. (2001), Democracia, educación y multiculturalismo, México, Siglo XXI.

YOUNG, I.M. (2000), La justicia y la politica de la diferencia, Madrid, Cátedra. 